\title{
Microstructure and Corrosion Resistance of Electrophoretic Deposited Carbonated Hydroxyapatite-Graphene Oxide Composite Coatings on AZ91 Magnesium Alloy
}

\author{
Zishan Chen, Wei Wang ${ }^{*}$, Qimin Liang, Weiming Lin \\ School of Materials Engineering, Shanghai University of Engineering Science, Shanghai, 201620, \\ China \\ *E-mail: wangwei200173@ sina.com
}

Received: 7 July 2021 / Accepted: 25 August 2021 / Published: 10 October 2021

\begin{abstract}
Carbonated hydroxyapatite-graphene oxide (GO) composite coatings were obtained on AZ91 magnesium alloy using electrophoretic deposition from isopropanol suspensions. The results showed that ultrasonic treatment exfoliated $\mathrm{GO}$ sheets and promoted $\mathrm{CO}_{2}$ adsorption on the surface of GO sheets. Subsequently, B-type carbonated HA was generated during ultrasonication-assisted EPD. The experimental results manifested that microstructures and porosity, carbonated HA content and the formation of GO-Mg complexes in pores/cracks had a significant synergistic effect on improving corrosion resistance of AZ91 magnesium alloy. HA-GO-0.33 composite coating had shown superior performance of corrosion prevention in the $0.9 \mathrm{wt}$. $\% \mathrm{NaCl}$ solution which provided some corrosion theoretical basis for the application of $\mathrm{Mg}$ alloy in the direction of human implantation.
\end{abstract}

Keywords: Magnesium alloy; Graphene oxide; Carbonated hydroxyapatite; Corrosion resistance; Electrophoretic

\section{FULL TEXT}

(C) 2021 The Authors. Published by ESG (www.electrochemsci.org). This article is an open access article distributed under the terms and conditions of the Creative Commons Attribution license (http://creativecommons.org/licenses/by/4.0/). 